\title{
The Conflict of Realism and Surrealism in Anime Movies - Taking the Works of Hayao Miyazaki as Examples
}

\author{
Xianfeng Gong, Bin $\mathrm{Li}^{*}$ \\ Department of Communication and Media, Guangzhou Huashang College, Guangzhou 511300, Guangdong Province, \\ China \\ *Corresponding author: Bin Li, riwei993799@163.com

\begin{abstract}
Anime movie is a branch of cinematics. Unlike traditional movies, anime movies stand out with special characteristics in terms of how they shape the personality of the characters and how they portray the inner world of those characters. "Realism" and "surrealism" are important elements in anime movies to portray the stories. In this article, the special aesthetic of anime movies is analyzed using the works produced by Hayao Miyazaki. The internal conflict between "realism" and "surrealism" is analyzed in order to understand the character image and story theme in an in-depth manner.
\end{abstract}

Keywords: Anime movie; Realism; Surrealism; Hayao Miyazaki

Publication date: December 2021; Online publication: December 27, 2021

\section{The narration and the "reality" in anime movies}

Whether if it is an anime movie, story movie, or documentary in general, storytelling is always the most important aspect in the production of a movie. The art of narration and the narrative technique of an anime movie directly affect the development trend of the movie. However, in the production of an anime movie, it is necessary to understand the setting deep enough before agreeing on a narration. The market of anime movies belongs to children and teenagers, so anime movies should fit the mindset of children - the nonlogic, unconventional, nonlinear thinking of children. This kind of mindset has determined the outlook and narrative characteristics in some ways. There is "personification" in everything. "Personification" originates from the rough mindset of humans at an early stage. It reflects the "start" of humans in the primitive society - the mindset of a toddler. Lucien Lévy-Bruhl once said, "The world surrounding primitive man is itself mysterious. In the collective representation of primitive man, every existence, every item, and every natural phenomenon, are not how what we think they are now ${ }^{[1]}$."

The problem of "realistic" in anime movies is an important focus relating to the expression of arts in anime movies and its internal logic remaining in the market. In anime movies, dealing with the problem of "realistic" brings a dilemma between "realism" and "surrealism," in which it is difficult to please both sides. Of course, as for the way these artworks are portrayed, narratives in anime movies can make use of visualization to present artworks that fit the imagination of children. Anime is a kind of art that is full of imagination. Simply denoting its relationship with reality, the scenes in anime movies are usually nonexistent and are far beyond reality. In animation films, the immortal arts of controlling the clouds and fog, the various interpretation of magic, the "super humans" who have incredible secret abilities, and even omnipotent robots bring the audience into a surreal and impossible world. That is to say, animation production itself provides infinite possibilities for artistic imagination, and therefore, exaggerated 
deformations, non-logical resurrections, arbitrary galloping in the sky and underwater, etc. can be commonly appreciated in these productions. It can be said that anime does not reject any imagination and "impossibility" as it is born out of imagination, and then it is used to express the existence and emotions that are most suitable to be in imagination ${ }^{[2]}$.

The inner world of anime artists perfectly connects with the inner world of children. Therefore, by digging deeper within and drawing on the originality of their minds, they are able to achieve proximity and communication with the inner world of children.

\section{The expressive tension and innate flaws in anime movies}

Any kind of art has its own special way to express itself. Anime movie is a visual art. Visual art has a unique advantage but also innate flaws in artistic aesthetics. The "visualization" technique used in anime movies makes the characters seem alive on screen and brings the audiences closer to the actors; however, these created images have destroyed the imagination and the literary tone people would have explored themselves. This is similar to how a German literary scholar, Gotthold Ephraim Lessing, discussed the two concepts - "eyes of the heart" and "blind," in his book, Laocoon. When Lessing compared the differences between poetry and painting, he mentioned, "The similarity between Milton and Homer lies in blindness. Milton certainly does not provide the subject matter for an entire gallery of paintings, but if I am using my physical eye, the vision of my physical eye is equally the vision of my eyes in the heat. Blindness means that this limitation is removed; hence, I have to see blindness as having the greatest value instead. Historians can recount the most picturesque things in the most anti-picturesque ways ${ }^{[3]}$." Lessing spoke against the views of Kloos. Kloos proposed that the more imagery and movement a poem provides, it is more valuable; otherwise, the poem is considered "blind." However, Lessing disagreed with Kloos, in which he believes that the emotions a poet express cannot be confined within an image; it may be hazy and intentional, but they should not be seen with one's physical eyes; in fact, a poet watches and observes with his or her "eyes of the heart." For Lessing, the concept of "eyes of the heart" reflects an internal sight, rather than just images. The "eyes of the heart" provide a more ethereal, lingering, lasting, and relish taste. The second point that Lessing wanted to be reinforce is if unsightly objects like stools are pictured directly through painting, television, and films, many artworks would be destroyed. In contrast, words can do whatever they want, they can be poetic and picturesque. Images (film and drama) become filters in adapted literature masterpieces; they break the mystery of these works, bluntly showing them to the viewers. They filter out the valuable literary atmosphere, mood, sound, and colors, which cannot be expressed in dialogues or through simple pictures. The most subtle, detailed, and memorable things are filtered out. In most cases, what remains is just a rough and basic story. Using The Dream of Red Mansion as an example, its literary atmosphere, mood, tone, sound, and colors are the most important aspects. Adapting the novel into a drama or a movie, after watching the "image" version, the ones who truly understand The Dream of Red Mansion would feel as though they were being cheated. Many of them are more willing to keep their own lively understanding and comprehension of the novel; they prefer the special aesthetics of The Dream of Red Mansion compared to the ones locked in the actor's face, body, words, movement, and scenes ${ }^{[4]}$.

By looking at Lessing's perspective, it is not difficult to appreciate that anime movies, as "visualized" medium artworks, have a visual impact that writings do not possess, but they lack the unique aesthetic experience of literature. With the development of the mass media, and in particular the rise of new media, the world has entered the era of the "global village," predicted by McLuhan. The change of the media environment has resulted in variations in the appreciation and aesthetic of approaching art. The literary critic, Miller, proposed the end of literature. Theoretically, he had a deep relationship with Derrida, who was a master of deconstructive criticism. Derrida had a strong influence on Miller. In Miller's literature, Will Literary Studies Survive in the Age of Globalization?, he announced the end of the literary age with a 
direct quote from Derrida's The Postcard: "An entire epoch of so-called literature, if not all of it, cannot survive a certain technological regime of telecommunications (in this respect the political regime is secondary). Neither can philosophy, or psychoanalysis. Or love letters ${ }^{[5]}$."

Miller's argument is tantamount to explaining that the most fundamental reason for the survival of literature is distance, that is why they are so charming, and that the age of electronic media, also known as the internet, has reduced the distance to zero. The cost of aesthetic appreciation has reduced to zero; thus, literature is being treat like fast food. Without taking a deep look in any of them, just a glimpse, consumers just swiped over. Even love letters have lost their basis for survival; that ambiguity and fizzle between lovers ground down to nothing. It is clear that the objective necessity of a love letter, as a form of correspondence, lies in the distance between the writer and the recipient of the letter. McLuhan's notion of the "global village," or the zeroing out of distance, has shaken or subverted the necessity of love letters from its roots. This has the same meaning, interpretation, and is significant to the visual medium art form of films and videos.

\section{The confusion of "reality" in anime movies: realism and surrealism}

The ideological and existential logic of animation is that it expresses "reality." Animation often reveals the deepest emotions and love in human beings, and that is why animation is realistic. According to Henry Moore, the art of animation is not merely a kind of pleasure to one's visual and audio senses, but an expression of the meaning of life and a greater stimulation of life force. Cahill once eloquently put it, "Art becomes the fulfilment of our deepest and inevitable natural instincts ${ }^{[6]}$." The art of animation evokes a deep-seated "homesickness" among the audience. "Homeland" does not only symbolize the good old days of mankind, but also reflect a desire to compensate for contemporary conditions as well as feelings of absence and confusion. With modern technological interventions, the destruction of nature, the decline of religion, and ecological imbalance, the aesthetics of art are in danger of being demystified. It was once said that animation reflects the primitive memories and natural instincts that have been existing in human beings since the origins of art, enabling people today to visit their original home of life and to examine the reality of it ${ }^{[2]}$. Therefore, from this perspective, anime movies are faced with a profound contradiction of their own: they do not only have to reflect the current state of the society, but also to transcend reality and strike a balance between "realism" and "surrealism." It is a balance between pleasure and rationality, between promoting the sensual desires of human beings through playful scenes and inspiring reflection on reality through the art of laughter. Many scenes in anime movies even combine the sacred with the vulgar, the sublime with the inferior, the great with the small, and the wise with the stupid; such contrasting, antithetical subjects or values are challenging to the audience. They turn life upside down with a carnival attitude and make the audience believe that such banal pleasures are possible. As Nietzsche once said, "How can we not feel with the face of a joyful crowd? This joy may be fleeting, it may be illusory, but it is of vital importance to the human experience. Amine always shows a high degree of affirmation of life, a positive attitude, and a burgeoning atmosphere of will to live. In order to create this atmosphere, anime often features scenes of mass celebration, such as large rituals, dance scenes, and scenes of releasing oneself. In this collective revelry, the audiences have a new experience that breaks the limits of their existence, and the elements that make up a tense existence are relieved in this way. In this state, the tension of existence is relieved ${ }^{[2]}$."

All in all, "realism" should be the highest level of pursuit for anime movies. How to reflect reality through surreal techniques? How to achieve the human pursuit of truth, while delighting the audience's mind at the same time? The perfect marriage between technical skills and artistic aesthetics requires a careful design on the part of the creators. A masterful piece of art must be well crafted. It is also necessary for animation films to constantly seek a path of change and development. There is a need for breakthroughs 
in the narration, creation, technical innovation, and commercial operation models of anime movies.

\section{Breaking the boundaries in anime movies - An analysis of Hayao Miyazaki's anime movies}

Hayao Miyazaki represents the pinnacle of Japanese animation and commerce, and he is known as the "god of animation," a "national treasure," a "poet of animation," and a "national film author." What is it about Miyazaki's anime movies that make them so special?

\subsection{Well-conceived themes}

A blend of the real and the ideal. Hayao Miyazaki is a wise man, who have knowledge in many different disciplines, cultures, and areas. Due to the influence by both traditional and modern Japanese cultures, Miyazaki has drawn inspiration and themes from a wide range of sources. He has been looking through legends, mythological epics, novels, essays, philosophical writings, and comics from around the world. Miyazaki's animation is characterized by its variety and freedom of expression. While the themes of Miyazaki's works are diverse, they are relatively constant, following a certain style - a mankind perspective. Miyazaki stamps his works with extremely deep and heavy ideological themes, displaying his thoughts on various social problems that are in tune with the pulse of the times and era. He does not only draw beautiful pictures, but there is always a deeper meaning attached to them for his audience to think about. Miyazaki has overcome many difficulties to improve the quality of his work. He has reached a balanced point, where he is able to portray a realistic cinematic effect along with a surreal mood in his works. In view of the global significance of his themes and his technical mastery, his creations have transcended geographical boundaries and gained widespread recognition in the animation world.

The world is now confronted with increasingly serious environmental problems and crises: global warming, land desertification, energy depletion, and most recently, the sensational Japanese nuclear leak crisis. All these have led to a growing concern for nature and the reflection as well as action in response to one's own behavior. Miyazaki is dismayed by the destruction of the natural environment for the sake of creating civilization, the rush to profit, the widespread money-grubbing, and the growing indifference to family and loved ones in modern society. In his works, it can be appreciated that he repeatedly expresses his philosophical reflection on the relationship between humans and nature as well as his search for the meaning of human existence ${ }^{[7]}$.

\subsection{Characters with full of personality and originality}

The key to telling a good story within a limited time is to successfully portray the characters in such a way that can capture the audiences' eyes. Syd Field once said, "Character is the fundamental foundation of your screenplay; it is the heart, soul and nervous system of your screenplay ${ }^{[8]}$." Miyazaki heeds the principle of realism when creating his characters, so that his animation characters form a certain proportion to reality. Miyazaki portrays characters with great individuality and with his personal style. He shapes typical characters in typical environments.

In general, the basic elements of Miyazaki's unique characterizations are a standardized mix of young boys and girls, a stylized antagonist, and a small group of personalized supporting cast. Miyazaki's portrayal of young boys and girls is characterized by a standardized mix of characteristics. Almost every anime of his, has a young boy and a young girl in it; the combination of a brave or naive boy and a soft or strong girl is the classic standard used by Miyazaki, also containing a hidden element of pure love. For example, Haku and Chihiro in Spirited Away, Haku is portrayed as a brave boy while Chihiro as a tender, protective girl; in Kiki's Delivery Service, Tombo is an urchin while Kiki is a strong and staunch witch; other than that, the pairing of the magical prince and the kind and strong Sophie in Howl's Moving Castle. 
It is fair to say that a significant proportion of audiences watch Miyazaki's films for the sake of the love match between the young boys and girls in his anime.

\subsection{Ethnic culture and exoticism}

"The Japanese are extremely aggressive yet gentle; martial yet beautiful; proud and dignified yet courteous; stubborn and unyielding yet soft and fickle; tame yet reluctant to be manipulated; loyal and brave but also mutinous and timid; conservative yet open to new ways of life. They are mindful of what others think of their behavior but are overcome by sin when others are ignorant of their misdeeds. Their armies are thoroughly trained yet rebellious [9]," said Ruth Benedict, an American scholar, in her book, The Chrysanthemum and the Sword. As the title suggests, the author used two contrasting images, one that is rigid and the other being tender, to symbolize the contradictory character of the Japanese people or the two poles of the Japanese culture that are in sharp conflict yet strangely harmonious.

Hayao Miyazaki's anime movies are very much the direct products and representations of the Japanese culture. The Japanese culture is based on Shinto and Bushido. Miyazaki's anime is heavily influenced by these spirits as illustrated in his animations. Since the 1980s, Miyazaki's anime has been a proud national cultural symbol of Japan, based on its own cultural traditions, but with an exotic twist; this is also a characteristic of Miyazaki's anime. Japan is an island nation with limited resources, but the Japanese are enterprising people who look to the world to find a way to move forward, which makes it possible for Miyazaki's anime to have an exotic feel.

Hayao Miyazaki's exotic style coincides with the international "mainstream animation" genre. "Mainstream animation" refers to anime movies produced in the style of Disney, which dominate the market. Miyazaki's exoticism did not only enhance the entertainment and objectivity of his films, but also cater to the taste of a wider audience, branding Miyazaki's films as "mainstream" and "global."

\section{Disclosure statement}

The authors declare that there is no conflict of interest.

\section{References}

[1] Breuer L, 1981, Primitive Thinking [Ding Y, Trans.], The Commercial Press, Beijing, 28.

[2] Tang Z, 2010, Expansion, Reconstruction and Watch - Reflection on the "Authenticity" of Animated Films in the Digital Context. One Hundred Arts 2010(A01): 274-276.

[3] Lessing, 1982, Laocoon, People's Literature Press, 79.

[4] Tong Q, 2004, The Unique Aesthetic Field of Literature and the Entrance to Literature - A Dialogue with the Literary Finalists, The Final Conclusion of Art, China Social Science Press, 189.

[5] Miller H, 2001, Will Literary Studies Continue to Exist in the Age of Globalization?. The Literary Review, 1.

[6] Cassire E, 1988, Language and Myth, Sanlian Bookstore, Beijing, 186.

[7] Field S, 2002, The Foundations of Screenwriting [Bao Y, Zhong D, Trans.], China Film Press.

[8] Nie F, 2005, A Study of Hayao Miyazaki’s Anime Movies, Wuhan University Press, 9-13.

[9] Nie X, 2003, The Disney Complex of Hayao Miyazaki's Animated Films, Meng Jian, ConflictHarmony, Globalization and Asian Film and Television, Fudan University Press, 223. 